12. Олферьев А.Г., Алексеев А.С. Зональная стратиграфическая шкала верхнего мела Восточно-Европейской платформы // Стратиграфия. Геологическая корреляция. 2003. T.11, №2. C.75-101.

13. Стратиграфическая схема верхнемеловых отложений Восточно-Европейской платформы. СПб., 2004.

14. Бондарева М.В. О кампанских и маастрихтских породах междуречья Чира и Калитвы // Учен. зап. Сарат. ун-та. 1953. Т.XXXYІІ, вып. геол. С.62-70.

15. Барышникова В.И. К вопросу стратиграфии верхнемеловых отложений Хвалынско-Вольского района по фауне фораминифер // Учен. зап. Сарат. ун-та. 1951. T.XXVIII, вып. геол. С.65-77.

16. Стратиграфический кодекс. 2-е изд., доп. СПб., 1992. 120 с. (Межвед. стратиграф. ком.).

17. Рыков С.П. О стратиграфии верхнего мела бассейна $\mathrm{p}$. Медведицы // Учен. зап. Сарат. ун-та. 1951. Т.XXYІІІ, вып. геол. С.50-51.

18. Бондарева М.В., Морозов Н.С. Сеноманские, туронские и коньякские отложения междуречья Медведицы и Волги в пределах Волгоградского междуречья // Вопр. геологии Южного Урала и Поволжья. Саратов, 1984. С.62-70.

19. Иванов А.В. Каталог местонахождений маринакулат. Саратов, 1996. $106 \mathrm{c}$

20. Первушов Е.М., Иванов А.В., Попов Е.В. Альб-турон Поволжья: итоги исследований «рубежей» и «событий» // Проблемы изучения биосферы: Тез. докл. Всерос. науч. конф. Саратов, 1996. С.36-37.

21. Первушов Е.М., Иванов А.В. Сеноман Правобережного Поволжья // Геологические науки-97: Тез. докл. науч. конф. Саратов, 1997. С.20-21.
22. Первушов Е.М., Иванов А.В., Попов Е.В. Средне- и позднемеловая биота юго-востока Европейской палеобиогеографической области // Палеонтол. журн. 1997. №3. С.1-7. 23. Первушов Е.М., Иванов А.В., Попов Е.В. и др. Комплексное изучение опорных разрезов - основа разработки местной стратиграфической схемы верхнемеловых отложений // Геология и минеральные ресурсы юго-востока Русской платформы: Тез. докл. междунар. науч. конф., посвящ. памяти проф. В.В.Тикшаева. Саратов, 20-22 янв. 1998 г. Саратов, 1998. С.53-54.

24. Первушов Е.М., Иванов А.В., Гужиков А.Ю., Гришанов А.Н. Результаты комплексного изучения альбскихсеноманских отложений в разрезах «Меловатка-6» и «Красный Яр-1» (Волгоградская область) // Тр. НИИ геологии Сарат. ун-та. Новая сер. Саратов, 1999. Т.1. С.65-78. 25. Первушов Е.М., Архангельский М.С., Иванов А.В. Каталог местонахождений остатков морских рептилий в юрских и меловых отложениях Нижнего Поволжья. Саратов, 1999. 189 c.

26. Бондарева М.В. Геологическое строение и гидрогеологические условия северной части междуречья Волги и Медведицы (лист M-38-IV Саратов): Отчет Саратовской гидрогеологической партии по работам 1965-67 годов. Машинопись. Фонды. Саратов, 1967.

27. Первушов Е.М., Иванов А.В., Попов Е.В. Проект местной стратиграфической схемы верхнемеловых отложений Поволжья // Геологические науки-98: Тез. докл. науч. конф. Саратов, 1998. С.43.

28. Первушов Е.М., Иванов А.В., Попов Е.В. Местная стратиграфическая схема верхнемеловых отложений правобережного Поволжья // Тр. НИИ геологии Сарат. ун-та. Новая сер. Саратов, 1999. Т.1. С.85-94.

\title{
ИСТОКИ ГЕОЭКОЛОГИЧЕСКИХ ИССЛЕДОВАНИЙ В САРАТОВСКОМ УНИВЕРСИТЕТЕ
}

\author{
А.В. Иванов \\ Саратовский государственный университет, \\ кафедра геоэкологии \\ E-mail: geoecologia@info.sgu.ru
}

Существование природных опасностей по мере роста городов в Нижнем Поволжье сделало особо заметными геоэкологические проблемы в начале XX века. Их обострение вызвало активизацию преимущественно инженерно-геологических работ с элементами геоэкологических исследований, а также послужило импульсом для развития геоэкологических, градоэкологических, агроэкологических исследований особенно в последние два десятилетия.

\section{Origin of Geoecological Research in Saratov University}

\section{A.V. Ivanov}

Manifestation of natural disasters during growth of cities in the Volga Region revealed amount of geoecological problems in the beginning of the $20^{\text {th }}$ century. Increasing of these problems forced engineeringgeological research with elements of geoecological investigations in the Geological scientific Institute of Saratov University. This work provided a basis for geoecological, urboecological and agroecological research in the University.

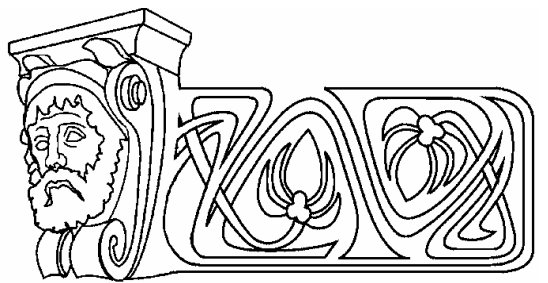

Геоэкология считается молодой наукой. Ее развитие как междисциплинарного научного направления наблюдается лишь около 30 лет. Однако и до этого описывались отдельные факты, появлялись идеи и попытки их реализации при проведении геологических и географических работ и исследований, связанных прежде всего с зонами урбанизации. Уже в XVIII-XIX вв. в литературе можно встретить фиксированные факты и краткие описания явлений, имеющих инженерно-геологическую и эколого-геологическую природу. Как правило, это яркие катастрофические события. Серия интересных данных содержится в записках протоиереев 
Г.А. и Н.Г. Скопиных, составивших подробный дневник природных событий (цит. по: [1]). Приведем выдержки из него:

«1783 г. Здесь в Саратове, в буераке с нагорной стороны много земли сползло и многия повредило там живущих избы. Иные с места долой спихнуло и некоторые сады повредило».

«1811 г. Июля 19-го. Еще нечаянность случилась в Саратове. Четыре дома, стоящих близ буераку горного, сползли в оный при обрушении яра. Так ненадежно жительство близ таковых мест».

«1818 г. В июле 19-го числа против Соколовой горы осела земля на всем протяжении повдоль Волги. Поселенные на сем пространстве домики, именуемые в затоне, более или менее искривлены и осели. Причиною сего полагать можно подмытие берегов Волгою. Она могла произвесть сие явление, вырыв ямы подле берегов. Земли сей пространство очень велико, и полагать можно, что составляет версту или более. Оседь в иных местах велика, в других мала. Но вообще, все сие пространство истрескалось».

В журнале Министерства внутренних дел $(1841$, ч. 40, с. 86$)$ говорится, что одной из причин этого оползня могло стать дождливое лето.

Краевед и журналист А.Ф.Леопольдов в 1848 г. опубликовал «Исторический очерк Саратовского края», в котором описал множество событий, в том числе связанных с геологическим субстратом - «оседи земли» в Глебучевом овраге и др. В этом и иных источниках зафиксирован сход крупного оползня в Хвалынском уезде в 1839 году. В издании «Русский инвалид» (1839, №198, с.801) это событие описано подробно. «Государственные крестьяне села Федоровки Хвалынского уезда с 16 на 17 июня сего 1839 года пробуждены были внезапным гулом и движением земли, а потом и сильным треском домов их. Не постигая причин, они, выбежав на улицы, с ужасом видели, что вся долина, на которой расположена большая часть села их, отторглась от подошвы горы, осела на значительную глубину и двинулась к реке Волге. Смятение народа достигло высшей степени, когда вся движущаяся масса стала волноваться, в одних местах подымать, а в других ниспровергать строения...
Образовались значительные выпуклости и углубления, а обширные и правильные трещины представили ряды торфа, как будто искусством созданных: там, где были болота и небольшие озера, выросли холмы, на местах же возвышенных оказались провалы, которые, как и многие трещины, наполнились водою. Самая же поверхность площади представляла зыбкой плот. Заметное волнение и движение земли продолжалось трое суток, потом постепенно все стихло... Повреждено 70 домов, некоторые разрушены вовсе; многие строения разорваны на несколько частей...» (цит. по: [2, с.400-401]).

А.Ф. Леопольдов уточняет, говоря об этом оползне, что «осадок долины сделался в длину 1,5 версты, в ширину - 250 саженей», а также пытается объяснить причины: «Долина, на которой расположена деревня Федоровка, примыкает к горам с восточной стороны и беспрестанно осаждается водами реки Волги. Против этого места, где образовался осадок земли, Волга особенно сжата берегами и, не находя свободного стока обильным водам своим, постепенно углубляет русло и подмывает правый берег, на коем стоит деревня Федоровка» (цит. по:[1, с.20]).

В конце XIX в. выходит уникальное справочное издание по землетрясениям [3], в котором затрагиваются и оползневые процессы. В этой работе описан крупный оползень 1865 г. в Симбирской губернии. «Вечером 15 мая после грозы с ливневым дождем, продолжавшимся более часа с четвертью, гора, на склоне которой было расположено село Порецкое, стала сползать к реке. Многие строения были повреждены. В воде у подошвы горы образовалось несколько островков. Утром 16 мая некоторые дома оказались опрокинутыми. Оползень произошел от размыва почвы подземными водами» (цит. по: $[2$, c.447]). Упоминается и о большом оползне 20 сентября 1884 г. в Саратове на Соколовой горе.

Интерес к геоэкологическим проблемам обострился в Нижнем Поволжье на рубеже $\mathrm{XIX-XX} \mathrm{вв.} \mathrm{в} \mathrm{связи} \mathrm{с} \mathrm{ростом} \mathrm{городов} \mathrm{[4].} \mathrm{Это}$ хорошо просматривается в исторических и художественных источниках, а также в саратовских СМИ начала XX в. Реакция на геоэкологические проблемы отражена в статье С.В. Клейменовой [5]. О такой экологически 
болезненной зоне города, как район Глебучева оврага, например, говорится: «Чем быстрее развивался Саратов, тем явственнее осознавался Глебучев овраг жителями как что-то недопустимое, позорящее их город. Беллетристические приемы, патетика появлялись в любом тексте, касавшемся оврага» [5, с.47-48]. Городской врач П.Н.Соколов в 1905 г. писал: «Здесь жилища поистине парий общества, среди навоза и отбросов, как собственных, так и остальных, более счастливых, жителей города. Здесь жилье - во многих случаях хуже, чем логовища животных. Здесь теснота построек поразительная; здесь все остальные условия существования настолько ужасны, что прямо удивляешься, как может человек со всем этим мириться, ко всему привыкнуть» [6]. По данным С.В.Клейменовой [5], журналисты прибегали и к стихотворным приемам. Так, сотрудник «Саратовского вестника» В. Добжинский (1913) в одном из своих фельетонов писал [7]:

«Две трещины продольные -

То Глебучев овраг

И недра Белоглинского.

В обоих гной и смрад».

Автор другого фельетона, наблюдая явную проблему загрязнений и отходов, саркастически сравнивал Саратов с Золушкой: «Города грязны и больны лишь потому, что не хотят быть чистыми и здоровыми. Но стоит лишь приказать - будьте здоровы! - и саратовская Замарашка с такими милыми складками (фестончики, везде фестончики!) на платье, как Глебов и прочие овраги, встряхнется и превратится в сказочную принцессу» [8].

В начале XX в. «Саратов разрастается с неимоверной быстротой, особенно по направлению к вокзалу» [9, с.137] и «характеризуется разрывом природного и искусственного окружения», что сопровождается сглаживанием холмов, застройкой склонов, нивелированием рельефа, исчезновением малых водоемов, изменением акватории Волги. В это время происходит утрата тех ценных моментов, которые имели место на первых этапах развития Саратова, прежде всего «гармонии искусственных построек и природного окружения города, когда архитектурная полихромия не только гармонировала с природным окружением, но и была его частью» [10].
В начале XX в. наблюдается увеличение числа работ по оползневым процессам в зонах урбанизации, в том числе по территории Саратовского Поволжья - работы А.П. Павлова, А.Д.Архангельского, А.Д.Стопневича и других известных исследователей. Особенно интересные и оригинальные описания оползневых явлений выполнены А.П. Нечаевым. Приведем пример его описания крупнейшего оползня 20 сентября 1884 г. на Соколовой горе: «Еще за несколько дней до катастрофы земля начала медленно оползать к Волге, покрываясь на поверхности трещинами и буграми. По ночам слышались треск домов и звяканье лопающихся стекол. Полы в домах приподнимались, печи давали трещины. Многие из предусмотрительных жителей, заметив эти зловещие явления, поспешили покинуть свои дома. В 11 часов утра 20 сентября вдруг движение земли сделалось быстрым, и значительная часть горы с шумом обрушилась в реку. Во всем Саратове дрожала земля, раскачивались висячие лампы, останавливались часы, несколько домиков, расположенных на обрыве Соколовой горы, сорвались и полетели в пропасть. Крупные здания находившихся здесь фабрик и заводов переломились надвое, натрое, наклонились в сторону и некоторые совсем упали» (цит. по: $[11$, c.143-144]).

С точки зрения истории экологических наук в СГУ особый интерес представляют первые исследования, которые датируются 30 -ми гг. XX в. Информацию об этом можно почерпнуть из публикаций и фондовых отчетов тех лет, а также из в сводных годовых отчетов института геологии, представлявшихся ежегодно в Народный комиссариат РСФСР по просвещению.

Конечно, инженерно-геологические научно-производственные заключения, затрагивающие некоторые эколого-геологические аспекты, составлялись и ранее, однако систематический плановый характер исследования получили непосредственно после создания в 1935 г. в составе Саратовского университета научно-исследовательского института геологии. Интересно, что в $30-е$ гг. доля таких исследований составляла более половины тематического плана института, а по объемам фактического финансирования и того больше. 
В 1935 г., сразу же после основания НИИ геологии СГУ, ученым советом был принят программный документ «Главнейшие проблемы, разрабатываемые Институтом в 1935 году», в котором первоочередной значится «Камышинская плотина ирригации Заволжья». По этой проблеме было открыто ряд тем, касающихся вопросов инженерной геологии территории ирригации и геологии Камышинского створа. Результаты работ использованы Нижневолгопроектом.

В 1936 г., по мере развития института, инженерно-геологические работы были резко расширены. В течение года было дано свыше 50 инженерно-геологических заключений, многие из которых составлены на основе данных опытных инженерно-геологических исследований по изучению физико-механических и водных свойств грунтов, с определением их несущей способности. За время работы удалось собрать богатый материал для инженерно-геологической характеристики грунтов. На базе этого материала институт счел возможным наметить работу по инженерно-геологическому районированию территории Саратова, которая в связи с развитием строительства крупных промышленных и гражданских зданий являлась в то время крайне необходимой.

Активизировалась и приобрела системный характер работа по изучению оползневых процессов. На заседаниях НИИ в 1936 г. были заслушаны доклады ученого секретаря института В.Г. Камышевой-Елпатьевской «Оползни правобережья Волги на плесе Хвалынск - Саратов» и доцента В.С. Васильева «Оползни окрестностей г. Вольска и г. Саратова». В 1936 г. открыта тема по определению оползневых смещений на Увекском косогоре, предполагающая систему наблюдений во времени, фактически, исследования мониторингового характера. Результаты исследований публиковались в «Трудах научно-исследовательского института геологии Саратовского университета» [12].

В 1937 г. также наращиваются масштабы научно-практических работ, преимущественно инженерно-геологических. По договорам были выполнены следующие работы и даны консультации: для Саргипрогора - инженерно-геологическая характеристика грунтов территории «Нового города Энгельса», для Совнаркома АСС РНП - инженерногеологическое заключение о строительстве Дворца Советов в Энгельсе, для завода «Комбикорм» - заключение об оползне косогора и заключение к восстановлению завода, для Саратовского мединститута - консультация по вопросу устройства дренажа на территории здания общежития, для Драмтеатpa - консультация о несущей способности грунтов под строительство здания, для Бронетанковой школы - заключение о несущей способности грунтов под строительство школы, для Лентранспроекта - консультация по вопросу об исследовании оползней в Князевке, для СГУ - заключение о несущей способности грунтов стройплощадок.

По сектору геофизических исследований (руководитель доцент В.П.Лузин) в 1937 г. была открыта тематика, связанная с изучением микрооползневых движений на неустойчивых массивах Волжского побережья и предполагающая фактически эколого-геофизическое исследование с использованием мониторинга.

В 1938 г. СарТЭЦ-2 дана консультация и составлен отзыв о работе Коровина «Проект укрепления Увекского оползня». В этом же году по заданию Сароблпроекта В.Н. Кузиным и М.П. Борчаниновым под общим руководством директора института, профессора Б.А.Можаровского написан «Инженерно-геологический и гидрогеологический очерк территории города Саратова» по результатам работ и заключениям Института геологии СГУ, Геологического управления, Сароблпроекта и Архитектурно-планировочной мастерской.

По сектору геофизических исследований в 1938 г. открыта тема «Устойчивость геодезических знаков в условиях оползневых косогоров речных долин» (руководитель В.П. Лузин), в основном направленная на изучение микродвижений оползневых косогоров Саратовского правобережья р.Волги. С вопросами подвижек грунтов на волжских косогорах - на Увеке, Князевке, на Соколовой горе Институту геологии постоянно приходится встречаться в связи с составлением инженерно-геологических заключений по строительству на оползневых косогорах. Таким образом, заключается в сводном отчете НИИ геологии СГУ за 1938 г., «сведения о 
движениях оползней представляют не только научный, но и глубоко практический интеpec».

Большая работа по изучению инженерно-геологических условий территорий города Саратова проводилась по заданию различных организаций и учреждений. Вопросами инженерной геологии и гидрогеологии занимались доцент В.Н. Кузин и профессор Б.А. Можаровский. К работам были привлечены студенты старших курсов геологического отделения: Борчанинов, Меньшиков, Светлов, Таганов и др. За 1938 г. составлено более 60 заключений по инженерной геологии и функционированию природно-техногенных систем. Консультации по этим вопросам давались практически ежедневно.

В связи с развитием инженерной геологии с каждым годом все более и более ощущалась необходимость в организации специальной геотехнической лаборатории. В обосновании, представленном учеными института в Наркомпрос, было сказано: «Необходимость организации такой лаборатории диктуется запросами, которые поступают в Институт геологии со стороны различных организаций и учреждений, как местных, так и центральных. Совершенно бесспорным является то, что в связи с развитием промышленности и грандиозным строительством на ЮгоВостоке запросы по геотехническим свойствам грунтов возрастут. До настоящего времени в Саратове не имелось специальной лаборатории и недостаток в таковой сильно ощущался. Заказы, которые могли бы быть выполнены в Саратове, часто отправлялись в Центр и только в незначительной своей части выполнялись в лаборатории Автодорожного Института». В 1938 г. Институт геологии пригласил специалиста по точной механике А.А. Функа, под его непосредственным руководством в механических мастерских г. Саратова и г. Камышина были изготовлены приборы инженера Терцаги по снятию компрессионных кривых грунтов, а также для определения фильтрационных свойств грунтов и др.

В результате Институт был оснащен точными инструментами и приборами, позволяющими изучать геотехнические свойства грунтов и оборудовать специальную геотехническую лабораторию. Открытие лаборатории задержалось лишь потому, что «Ин- ститут, располагая специалистами, не имеет специально оборудованного для этой лаборатории помещения и средств для найма и приспособления помещения» (из отчета в Наркомпрос). Лаборатория открылась в следующем, 1939 г., что резко расширило возможности Института по выполнению заказов учреждений на изучение геотехнических свойств грунтов, проведения научных исследований и практических занятий со студентами.

В 1938 г. НИИ геологии были проведены полевые работы в окрестностях г. Саратова, что диктовалось запросами ряда организаций и учреждений города в связи с планировкой и водоснабжением его окраин - 1-й и 2-й Дачных. Эти же задачи были поставлены по просьбе саратовского Горсовета в связи с затруднениями водоснабжения, которые обострились за несколько крайне засушливых лет, вызвавших снижение дебитов родников и колодезных вод. Собранные данные были использованы при составлении инженерно-геологического очерка территории города Саратова и заключения о перспективах возможности водоснабжения подземными водами 1-й и 2-й Дачных.

Интересно отметить, что эти работы выполнялись студентами старших курсов под руководством Б.А. Можаровского. Сбор инженерно-геологических данных в правобережье р.Волги между оврагом Сеча и Увек осуществляли студенты Живолуп и Строганов, гидрогеологическое обследование Дачных остановок проводили Бекетов и Ларин.

В 1939 г. под руководством старшего преподавателя В.Н. Кузина была проведена инженерно-геологическая оценка грунтов территории Саратова, результаты выполнения которой послужили базой для составления проекта перепланировки Саратова.

Итоги названных исследований были представлены на научной сессии, проведенной в связи с 30-летним юбилеем Саратовского госуниверситета в ноябре 1939 г., где были, в частности, заслушаны доклады В.Н. Кузина «Инженерно-геологическая характеристика территории г. Саратова» и кандидата наук, доцента Н.Д. Грязева «Торф и отходы промышленности в Саратовской области как удобрительный материал». 
В 40-е гг. начались интенсивные исследования по проблеме отходов в Саратове. В 1940 г. в НИИ геологии по разделу агрохимии были открыты научно-исследовательские темы «Запасы и агрохимическая оценка отходов промышленности и городских отбросов в связи с использованием их в сельском хозяйстве» (руководитель доцент Н.Д. Грязев) и «Торф, фекалин и органические отходы промышленности как удобрительные материалы». Были заложены вегетационные опыты с испытанием фекальных масс, торфа и различных компостов под культуру томатов; проведены анализы на содержание в компостах азота, фосфора, углерода и калия; проведен анализ по Ваксману торфа из Бакурского района; изучено влияние фекальных масс на всхожесть томатов. Выполнялись также экспериментальные работы по теме «Производственные опыты с фекальными массами и исследования на опытном поле СГУ по испытанию компостов» (руководитель доцент Н.Д. Грязев). Результаты были представлены на научных семинарах, где, в частности, заслушаны и обсуждены доклады В.Н. Кузина «О гидрогеологических и инженерно-геологических условиях г. Саратова» и Н.Д. Грязева «Использование на удобрение городских отходов».

Получила развитие тема «Изучение местных органических удобрений Саратовской области (торф, ил, отходы промышленности, отходы города)» (руководитель Н.Д. Грязев). Она отвечала задачам третьего пятилетнего плана развития сельского хозяйства СССР и имела целью изучить различные местные органические удобрения и установить их роль в повышении плодородия почвы. Из отчета в Наркомпрос НИИ геологии СГУ: «Одним из важнейших условий создания высоких и устойчивых урожаев на ЮгоВостоке СССР является широкое использование на полях местных удобрений. Это с полной очевидностью доказано практикой передовых по урожайности колхозов и совхозов. Несмотря на это, далеко не все возможности в этом направлении используются. Многие органические комплексы, имеющиеся в Саратовской области, совершенно не используются как удобрения. К таким органическим комплексам мы должны отнести: торф, прудовой ил, отходы промышленности и отходы города».
На первых этапах изучения органических комплексов проводились: их количественный учет для выяснения удельного значения как возможных удобрительных средств; определение химического состава; установление способов использования органических комплексов на удобрение. В результате исследований 1939 г. было вычислено, что в Саратове ежегодно накапливается 258 тыс. т мусора и уличного смета, 50 тыс. т фекальных масс и 15 тыс. т разных промышленных отходов. Удалось определить также химический состав этих отбросов (таблица).

Состав отходов города (составил Н.Д.Грязев - из отчета НИИ геологии СГУ, 1939)

\begin{tabular}{|l|c|c|c|}
\hline \multirow{2}{*}{\multicolumn{1}{|c|}{ Вид отхода }} & \multicolumn{3}{|c|}{$\begin{array}{r}\text { Содержание на сухое вещество } \\
\text { соединений, \% }\end{array}$} \\
\cline { 2 - 4 } & азота & фосфора & калия \\
\hline Домовой мусор & 0,54 & 0,55 & 0,42 \\
\hline $\begin{array}{l}\text { Фекалит из отстойни- } \\
\text { ка после двухмесяч- } \\
\text { ной сушки }\end{array}$ & 5,39 & 2,80 & 2,30 \\
\hline Подзол & 0,36 & 0,57 & - \\
\hline Отлубина & 1,09 & 1,35 & - \\
\hline Подсолнечная лузга & 1,04 & 1,35 & - \\
\hline Клейрот клещевинный & 10,63 & следы & - \\
\hline Шрат & 9,38 & - & - \\
\hline Пыль табачная & 4,31 & 0,43 & - \\
\hline Каныга & 0,83 & 0,33 & - \\
\hline
\end{tabular}

По данным Н.Д. Грязева, если сделать перерасчет соединений азота, фосфора и калия, содержащихся во всем годовом накоплении органических отбросов, на минеральные удобрения, то получится 26 тысяч тонн. В отчете НИИ геологии в Наркомпрос сказано: «Организуя компостирование городского мусора, мы можем получить для пригородных плодоовощных хозяйств громадное количество ценных удобрений, освобождая тем самым железнодорожный транспорт от перевозки минеральных удобрений. Такой же богатый источник удобрений может дать очистительно-канализационная станция Саратова в Улешах в виде отстойных масс. За не один десяток лет этих отстойных масс скопилось на станции в Улешах громадное количество». Возможные пути использования отстойных фекальных масс на полях под культуры, не употребляющиеся в свежем виде, прорабатывались в 1940 году. 
Согласно выводам Н.Д. Грязева, ценность отходов промышленности г. Саратова как удобрений различна. Подзол практически не может быть использован на удобрение изза высокого содержания в нем кальция и наличия сернистого натрия, вредно действующих на культурные растения. Клейрот клещевинный, табачная пыль, каныга, отбузина могут быть применены как удобрения, но только после компостирования (удобрительная ценность после компостирования сильно увеличивается). Результаты работ нашли применение в районах широкой ирригации Заволжья.

По разделу агрохимии, кроме того, выполнялась госбюджетная работа «Азотный фонд каштановой почвы в севообороте с люцерной при орошении». В результате выделены, очищены и проверены на культурные признаки шесть штаммов клубеньковой бактерии люцерны; выделен новый штамм этой бактерии для желтой люцерны, возделываемой без орошения; выполнены лабораторные и производственные опыты по определению активности и вирулентности клубеньковой бактерии (местных штаммов); проведены исследования корневой системы люцерны в полевых условиях (ВОМС и Краснокутская опытная станция); проведены лабораторные опыты, связанные с распадом органического вещества корней и стерни люцерны в чистом виде и в почве. По итогам работ Саратовскому Облплану сделано указание на способы хранения и переработки городских нечистот на удобрение для пригородных овощных совхозов.

После окончания Великой Отечественной войны была возобновлена деятельность НИИ геологии, в котором снова развернулись многоплановые исследования, требовавшиеся для восстановления страны. За последующие годы в истории исследований в СГУ произошло много событий. В первой половине 70 -х гг. в результате развития соответствующего научного направления была создана отдельная кафедра гидрогеологии и инженерной геологии, ставшая ареной исследований и подготовки специалистов. Относительно недавние значимые события - открытие геоэкологической специальности (1995) и кафедры геоэкологии СГУ (2002) [13].
Основные направления исследований $30-\mathrm{x} \mathrm{гг.} \mathrm{являются} \mathrm{определяющими} \mathrm{и} \mathrm{сегодня.}$ В довоенное время создан серьезный научнопрактический задел, его потенциал реализуется и в настоящее время. Конечно, за прошедшее время появились новые методики, новые аспекты исследований, однако налицо главная тенденция - усиление внимания к антропогенным причинам геологических процессов и их влиянию на урбосистемы и человека. Обозначим эти преемственные направления.

1. Градоэкологическое направление. В настоящее время исследованиями этого направления занимаются сотрудники лаборатории урбоэкологии Саратовского университета. Характерно интенсивное развитие, практическая значимость в связи с постоянной необходимостью решения многочисленных экологических проблем Саратовской природно-техногенной системы, расширение сферы исследований, в том числе историкоградоэкологических [14]. На сегодняшний день создан мощный современный инструментарий: геоинформационные технологии, методы дистанционного зондирования.

2. Изучение проблемы отходов и загрязнений. По мере эволюции Саратовской природно-техногенной системы значительно расширился спектр загрязнителей и доля отходов повышенных классов опасности. В последнее десятилетие интересные данные по загрязнениям дает снеговая съемка. Стало возможным развитие крупных проектов. В Саратовском госуниверситете прошли две Всероссийские научно-практические конференции по вопросам подземного захоронения промышленных отходов, появились совместные проекты по этой тематике (Российский университет Дружбы народов, ИГЕМ РАН и др.). Реализован проект по тяжелым металлам совместно с Институтом устойчивых сообществ (Москва), ИГЕМом и др.

3. Изучение геодинамических процессов и их эколого-геологических аспектов оползневой опасности, изменений овражнобалочной сети и др. Исторический подход развивается не только в градоэкологических, но и в эколого-геологических исследованиях. Обычно считается, что антропогенное (техногенное) воздействие, способное вызвать ощутимое влияние на геологические процес- 
сы (например, на активизацию оползневой опасности), имеет место на территории Саратова и его окрестностей лишь в последние несколько десятилетий. Однако имеются данные, позволяющие обсуждать возможность подобных проблем у наших предков. Примером может служить гибель средневекового города Укека, располагавшегося в пределах территории современного Саратова. Исследования показывают реальность сценария гибели Укека в результате крупного оползня (каскада оползней), возможно, спровоцированного и (или) сопровождавшегося взрывом (серией взрывов) природного газа. Причем в подготовку и реализацию такого сценария внесли свой вклад помимо классических природных причин также антропогенные, связанные с воздействием на литосферу, - бесконтрольная добыча глин, выемки грунта в строительных целях, обводнение в результате устройства садов и фонтанов и др. [15].

Ныне в Саратовском госуниверситете геоэкологические исследования охватывают весь комплекс учебных и научных подразделений, работающих в области наук о Земле: геологический и географический факультеты, НИИ геологии, Геологический колледж, лаборатория урбоэкологии. Исторически они развивались несколько специфично, что диктует необходимость создания единой концептуальной основы направления [16].

Обзор работ с элементами геоэкологических и градоэкологических исследований позволяет сделать следующие основные заключения.

1. В развитии геоэкологических идей и исследований в Саратове выделяется ряд этапов.

Первый (XIX в. - 30-е гг. XX в.) - этап осознания природных опасностей и фиксации фактов - преимущественно катастрофических ситуаций (оползней, обвалов и др.). Первые бессистемные попытки понять причинность этих событий.

Второй (30-40-е гг.) - этап активизации инженерно-геологических, агрономических исследований, увязанных в систему тематического плана НИИ геологии СГУ. Наблюдается появление в этих исследованиях геоэкологических, урбоэкологических и агроэкологических элементов.
Третий этап (50-70-е гг.) - расширение спектра инженерно-геологических работ, создание отдельной кафедры гидрогеологии и инженерной геологии. Появление экологогеологических исследований - анализ проблемы подтопления и др. Развитие градоэкологических исследований.

Четвертый этап (80-е гг. - сегодняшний день) - всплеск исследований с геоэкологическими и эколого-геологическими элементами во всех геонаучных подразделениях университета, открытие новых специальностей, создание новых структур (лаборатории градоэкологии, лаборатории геоэкологии, кафедры геоэкологии).

Эти этапы согласуются с этапами развития геоэкологии и экологической геологии в целом как науки [17], а также с развитием наук о Земле в Саратовском госуниверситете [18].

2. Появившиеся в 30-е гг. инженерногеологические исследования и научнопроизводственные изыскания имели элементы эколого-геологического характера. В это же время зародились элементы по сути междисциплинарных исследований урбоэкологического и геоэкологического характера. Например, исследования оползневой опасности велись комплексно с применением системы мониторинга. Комплексные почвенные, аграрные, биохимические и т.д. исследования (в те годы - Институт геологии и почвоведения) позволили привлечь данные о биотах, агроценозах и их взаимосвязях с геологическим субстратом и деятельностью человека. Это дает основание говорить о некоторых исследованиях как о геоэкологических в широком толковании геоэкологии [16].

3. Комплексными геоэкологизированными исследованиями 30-х гг. ХХ в. представляются работы по темам Н.Д.Грязева, продолжавшиеся несколько лет и включавшие обширную экспериментальную часть. Эти исследования носили междисциплинарный характер и затрагивали градоэкологические, агроэкологические и геоэкологические вопросы с изучением «проблемы отходов» и разработкой путей их утилизации.

4. На развитие исследований серьезно повлияла деятельность масштабной личности профессора Б.А. Можаровского - основателя и первого директора НИИ геологии СГУ. Его 
непосредственное руководство многими инженерно-геологическими изысканиями определило их значительное число, большие объемы, размах и широкий тематический спектр, быстрое внедрение результатов в учебный процесс, привлечение к исследованиям студентов. А эколого-геологические исследования, как известно, своим развитием и очерчиванием самостоятельной науки изначально обязаны именно инженерной геологии и смежным с ней направлениям в науках о Земле [17], что хорошо видно на примере СГУ.

5. В настоящее время в экологической геологии выделяют четыре так называемых экологических функции литосферы: ресурсную, геодинамическую, геохимическую и геофизическую [17, 19-21]. В 30-е гг. ХХ в. уже фактически проводились исследования всех этих функций, в особенности геодинамической.

6. Работы 30-х гг. стали мощным толчком их дальнейшего развития. Несмотря на сложности военного времени и периода восстановления, научно-практический задел 30-х гг. позволил в дальнейшем восстановить и приумножить инженерно-геологическое направление и начать развитие геоэкологического. Анализу работ того времени необходимо уделять больше внимания при проведении современных геоэкологических исследований на территории Саратова и всего Нижнего Поволжья.

Таким образом, инженерно-геологические и геоэкологические исследования в Саратовском госуниверситете имеют давнюю историю (НИИ геологии, в котором они получили системное развитие, работает уже 70 лет). Описанные первые, но уже достаточно мощные ростки инженерно-геологических исследований с геоэкологическими, градоэкологическими и агроэкологическими элементами явились импульсом развития соответствующих направлений.

Автор благодарит В.Б.Сельцера, Н.В.Добролюбову и Ю.Ф.Павлову за помощь в работе с фондовыми материалами.

\section{Библиографический список}

1. Семенов В.Н. Саратов геологический. Саратов, 2000. $384 \mathrm{c}$.

2. Борисенков Е.П., Пасеикий В.М. Тысячелетняя летопись необычайных явлений природы. М., 1988. 524 с.

3. Мушкетов И., Орлов А. Каталог землетрясений в Российской империи // Зап. Рус. Геогр. о-ва. СПб., 1893. Т.26.

4. Курбатова А.С., Мягков С.М., Шныпарков А.Л. Природный риск для городов России. М., 1997. 240 с.

5. Клейменова С.В. Из истории саратовской печати 1910-х годов // Изв. Сарат. ун-та. Новая сер. 2003. Т.3, вып.2. C.46-51.

6. Соколов П.Н. Санитарное состояние Саратовских оврагов Белоглинского и Глебучева // Саратовская земская неделя. 1905. №3. С.29.

7. Добжинский В. Всадник без головы / Диез // Саратовский вестник. 1913. 20 окт. С.4.

8. Григорьев-Патрашкин С.Т. Будьте здоровы! // Саратовец. 1909. №27. С.10.

9. Саратов // Волга. Путеводитель на 1913 год. СПб., 1913.

10. Терехова В.Ф. Влияние природной полихромии на колористическую среду города Саратова в процессе эволюционного развития // Саратовское Поволжье в панораме веков: история, традиция, проблемы: Материалы IX межрегион. науч. краевед. чтений. Саратов, 2000. С.300.

11. Рогозин И.С., Дунаева Г.В. Оползни Саратовского Поволжья. М., 1962. $162 \mathrm{c.}$

12. Труды научно-исследовательского института геологии Саратовского университета. Саратов, 1936. T.1. 275 с.

13. Иванов А.В. Новая кафедра геоэкологии в Саратовском университете: особенности появления и принципы развития // Изв. Сарат. ун-та. Новая сер. 2003. Т.3, вып.2. C.19-23.

14. Макаров В.З., Тарасова Л.Г., Чумаченко А.Н. и др. Историческая градоэкология: концептуальная основа, методология и практическая реализация на примере Саратова // Изв. Сарат. ун-та. Новая сер. 2001. Т.1, вып.1. С.89-101.

15. Иванов А.В., Браташова С.А., Сингатуллин Р.А. Эколого-геологические аспекты гибели средневекового города Укека // Недра Поволжья и Прикаспия. 2005. Вып.41. C.56-68.

16. Иванов А.В., Макаров В.З. К стратегии развития геоэкологического научно-образовательного направления в Саратовском университете // Изв. Сарат. ун-та. Новая сер. 2002. Т.2, вып.1. С.83-87.

17. Трофимов В.Т., Зилинг Д.Г. Экологическая геология. M., 2002.415 c.

18. Иванов А.В., Рыскин М.И. Концепция развития наук о Земле и глобальной экологии в Саратовском университете. Саратов, 2004. 86 с.

19. Теория и методология экологической геологии / Под ред. В.Т.Трофимова. М., 1997. 368 с.

20. Богословский В.А., Жигалин А.Д., Хмелевской В.К. Экологическая геофизика. М., $2000.256 \mathrm{c}$.

21. Экологические функции литосферы / В.Т.Трофимов, Д.Г. Зилинг, Т.А. Барабошкина и др. / Под ред. В.Т.Трофимова. М., 2000. 432 с. 